\title{
Effect of Trekking Shoes Midsole Hardness on Walking According to Backpack Wear
}

\author{
Seung-hyun Cho ${ }^{1}$, Kwan-tae Kim ${ }^{1}$, Jung-ho Lee ${ }^{2}$, \& Mi-sun Kim ${ }^{3 *}$ \\ ${ }^{1}$ Kookmin University ${ }^{2}$ K2korea shoe research lab, $\&{ }^{3}$ Korea Institute of Sport Science
}

\begin{abstract}
[Purpose] The purpose of this study was to investigate the effect of midsole hardness on gait mechanisms by wearing a backpack. [Methods] Ten healthy adult males(age:23.20 \pm 1.33 yrs, heights: $1.72 \pm 0.03 \mathrm{~cm}$, weights: $67.60 \pm 5.95 \mathrm{~kg}$ ) participated in this study. Subjects walked at a speed of $1.5 \mathrm{~m} / \mathrm{s}$ in an $8 \mathrm{~m}$ section wearing randomly selected midsole hardness (Soft, Medium, Hard) shoes and backpack (30\% of body weight). For measurement of body movement, 10 infrared cameras (Vicon motion capture system, UK) and force plate (AMTI, ORG-6, US) were used. [Results] First, in the shock phenomenon change, the ground contact time was longer when wearing a backpack. Second, in the shock absorption strategy, the pack plantarflexion velocity at the ankle joint was faster in Hard than Soft, and the pack dorsiflexion moment decreased when wearing a backpack $(\mathrm{p}<.05)$. Also, the pack extension moment of the knee increased significantly when wearing a backpack. Fourth, in the mechanical negative work, the ankle joint performed less work than the medium soft, and the knee joint increased as the backpack was worn $(\mathrm{p}<.05)$. [Conclusion] As a result of this study, the difference in the hardness of the midsole used in this study does not seem to affect the biomechanical movement of gait even when wearing a backpack. In future studies, it is necessary to investigate the effect of the midsole through the presence or absence of shoes or inducing muscle fatigue.
\end{abstract}

Key words: midsole, backpack, shock phenomenon, strategy for shock-absorbing, mechanical negative work

\section{서 론}

트레킹(trekking)은 배낭(backpack)을 메고 숲이나 언 덕, 산 등 자연환경을 따라 걷는 점에서 등산(hiking)과 비 슷하지만, 더욱 모험적인 길을 개척하며 장시간 걷는 산행 활동이다(Diffen, 2020; 김희성 \& 이재섭, 2010). 최근 국 내 산행 형태가 트레킹으로 점차 변화하는 경향을 보이며

논문 투고일 : 2020.10.26.

논문 수정일 : 2020.01.25.

게재 확정일 : 2021.03.04.

* 교신저자 : 김미선(imskyelove@gmail.com)

* 이 논문은 조승현(2020)의 석사학위 논문 중 일부를 발췌하였 고, 중소벤처기업부(MSS, KOREA)가 자금을 지원하는 기술 개발 프로그램(S2563279)의 지원을 받아 진행하였습니다.
(조선닷컴, 2019), 트레킹으로 인한 사고나 부상에 대한 안 전의 중요성이 대두되고 있다(Faulhaber et al., 2017; Monasterio, 2005). Schwameder와 Kraft, Alexander (2017)는 트레킹의 신체적, 기술적 요인과는 별개로 안정적 인 보행을 위하여 인체를 지지하는 신발에 초점을 맞추어야 한다고 하였으며, 실제 트레커들 또한 트레킹 시 가장 중요 한 장비로 신발을 선택하였다(조선닷컴, 2019).

신발의 구성은 크게 갑피(upper), 솔(sole), 힐(heel)로 나눌 수 있다. 솔은 인솔(insole), 미드솔(midsole), 아웃솔 (outsole)로 세분화할 수 있으며, 그중 미드솔은 인솔과 아 웃솔의 중간에 위치하여 지면으로부터 전달되는 충격력과 신체의 부하를 적절하게 분산시켜 발의 근육과 인대의 부담 을 줄여주는 중요한 역할을 한다(유찬일, 원용관 \& 김정자, 
2015; 김은경, 2000). Nigg와 Hintzen, Ferber (2006)는 적절한 쿠션의 미드솔은 발의 충격흡수를 보조하여 발의 부 상률을 감소시킨다고 하였고, Voloshin과 Wosk(1982)는 스포츠화의 미드솔에 충격흡수제를 넣었을 때 요추 통증 환 자의 $78 \%$ 가 통증이 완화되었다고 하였다. 그뿐만 아니라 Knapik 등(2009)은 미드솔의 쿠셔닝 소재가 발과 관련된 질병에 영향을 미친다고 하였으며, Stefanyshyn와 $\operatorname{Nigg}(2000)$ 는 미드솔의 점탄성 특성과 신발의 무게가 신체 에너지 소모에 영향을 미칠 수 있다고 하였다.

미드솔의 경도(hardness)는 인체 보행 중 충격흡수와 가 장 관련성이 높다. 그에 따라 많은 신발 전문가들은 보행에 가장 적합한 미드솔 경도를 찾기 위하여 연구를 진행해왔다 (Stacoff et al., 1988). 하지만 미드솔 경도의 차이가 보행 에 미치는 실질적인 효과는 여전히 연구자마다 이견이 갈린 다. Aerts와 Clercq(1993), De Wit와 De Clercq, Lenoir (1995)는 미드솔 경도가 부드러운, 즉 쿠셔닝(cushioning) 이 좋은 신발이 충격흡수에 효과적이라고 보고하였으며, 늘 어난 지면 접촉시간과 낮은 충격력, 충격량, 부하율과 같은 변인들의 변화를 근거로 제시하였다(Dixon, et al., 2003; Finestone et al., 1999; Lafortune, Hennig, \& Lake, 1996; Sterzing et al., 2013). 이처럼 부드러운 신발의 긍 정적인 연구 결과가 있는가 하면, $\mathrm{Ha}$, Ryu와 $\mathrm{Gil}(2020)$ 은 하지관절의 불안정성을 같이 언급하였다. 그들은 높은 쿠션 기능이 무게중심 이동에 대처하는 감각 기관의 기능을 저해 하고 고유수용감각(proprioceptor)의 피드백 전달속도를 느리게 하여 안정적인 자세 유지를 위하여 더욱 높은 신체 반응을 요구할 것이라고 하였다(Bergmann et al., 1995; Perry, Radtke, \& Goodwin, 2007).

한편 배낭은 트레킹을 실시하는 대부분의 사람들이 메는 이동 도구인데, 배낭 착용으로 인한 하중은 척추와 하지의
근골격계 질환의 발병 증가와 관련이 있다(Bentley, Page, \& Walker, 2004; Twombly \& Schussman, 1995). 이러 한 이유로, 트레킹은 누적 피로 절감과 안정적인 보행이 중 요하다. 실제 미국과 유럽에서는 등산 전문가를 신발 개발 과정에 직접 참여하도록 하여 품질 검사와 필드 테스트를 진 행한다. 그러나 배낭 착용 여부와 미드솔 경도 모두를 고려 한 효과의 연구는 미비한 실정이다. 만약 배낭 없이 걷는 인 체 보행에 효과적인 미드솔 경도가 존재할지라도, 배낭 착 용으로 달라진 보행 역학적 기전에 최적화된 미드솔 경도는 달라질 수 있을 것이다.

따라서 본 연구의 목적은 배낭을 착용함에 따라 트레킹화 미드솔 경도가 인체 보행 역학에 미치는 영향을 규명하는 것 이다. 연구 과제를 수행하기 위하여 미드솔 경도만 다른 트 레킹화를 제작하여, 배낭 착용 여부에 따라 보행의 운동역 학적(kinetics) 변인에 미치는 효과를 비교 분석하였다. 연 구 결과를 통해 배낭 보행 시 근 피로 절감과 역학적 안정성 에 효과적인 미드솔 경도를 제시하고자 한다.

\section{연구방법}

\section{연구대상}

본 연구에서는 최근 6 개월 이내 하지 근골격계 질환과 보행 시 신체적 결함이 없는 건강한 성인 남성 10 명(연령: $23.20 \pm 1.33$ 세, 신장: $1.72 \pm 0.03 \mathrm{~m}$, 체중: $67.60 \pm 5.95 \mathrm{~kg}$ ) 을 대상으로 실험을 진행하였다. 실험 전, 모든 대상자에게 실 험 절차 및 유의사항을 충분히 설명한 후 실험 동의서를 받고 진행하였다.

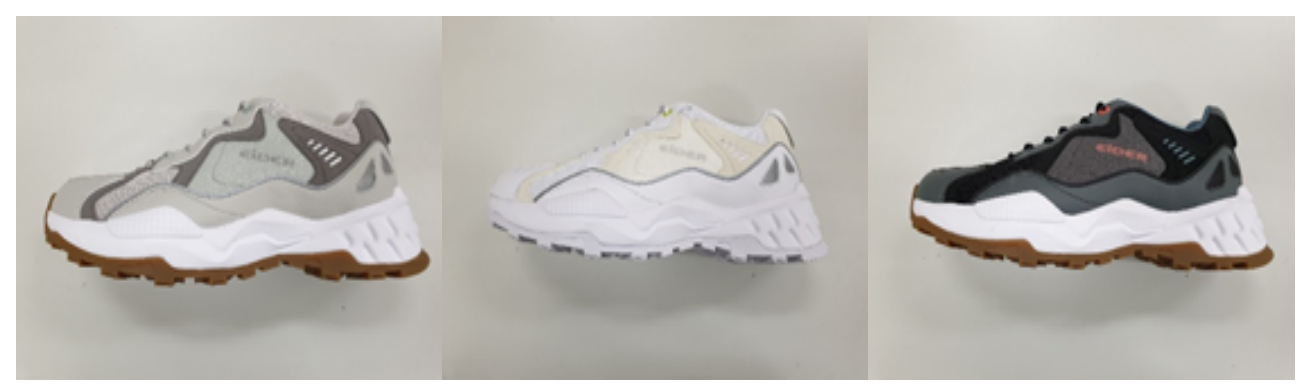

Fig. 1. 실험 신발(왼쪽부터 Soft, Medium, Hard) 


\section{실험 도구}

\section{1) 실험에 사용된 신발과 배낭}

본 실험에서 사용된 신발은 형태와 갑피, 뒤꿈치 높이, 아 웃솔과 제조 공장 등 신발을 구성하는 모든 물질적, 구조적 특성이 같은 3가지 트레킹화(Soft, Medium, Hard)를 사 용하였다(Figure 1). 미드솔의 특성은 〈Table 1〉과 같으 며, 밀도와 무게의 미비한 차이는 경도를 다르게 하기 위한 제조 과정에서 발생한 불가피한 특성이다.

Table 1. Midsole properties

\begin{tabular}{cccc}
\hline \hline 구분 & Soft & Medium & Hard \\
\hline $\begin{array}{c}\text { 경도 } \\
\text { (Asker C) }\end{array}$ & 53.0 & 63.0 & 68.0 \\
\hline $\begin{array}{c}\text { 밀도 } \\
\left(\mathrm{g} / \mathrm{cm}^{3}\right)\end{array}$ & 0.24 & 0.24 & 0.25 \\
\hline $\begin{array}{c}\text { 무게 } \\
(\mathrm{kg})\end{array}$ & 395.0 & 398.0 & 384.0 \\
\hline \hline
\end{tabular}

배낭은 $25 \mathrm{~L}$ 부피의 등산용 배낭(Eider, K2코리아, KR) 을 사용하였다. 그리고 본 연구에서 역학적 변인에 미치는 효과를 알아보기 위해서는 피로를 최소화시킬 수 있고, 인 체의 역학적 변인에 영향을 미칠 수 있을 정도의 무게를 적 용시키는 것이 중요하다고 판단되어 각 대상자 체중의 $30 \%$ 로 배낭의 무게를 설정하였다(Quesada et al., 2000; Haisman, 1988). 무게 조절은 웨이트 트레이닝용 원판을 삽입하여 조절한 후, 잔여 공간이 발생하는 경우 담요와 옷 가지로 채우고 측면에 버클을 조여 보행 시 흔들리는 것을 최소화하였다.

\section{2) 실험장비 및 실험방법}

본 연구 과제를 위하여 피험자가 미드솔 경도와 배낭 착용 여부의 각기 다른 수행 조건에서 걸었을 때 나타나 는 충격 현상의 변화(지면접촉시간, 최대충격력, 충격 량, 부하율), 인체 충격흡수 전략(하지관절의 최대 각속 도, 최대 모멘트, 기계적 음의 일) 그리고 보행의 동적 안 정성(발목 관절의 최대 각속도, 최대 모멘트, 기계적 음 의 일, 압력 중심의 좌우 편차)을 분석하였다.

개인의 보행 특성을 통제하여 미드솔 효과를 극명하 게 하고자 보행 속도를 통제하였으며, 이를 위해 구간 속력 측정기(Universal speed timer, Seedtech, KR)
를 활용하였다. 보행 시 인체의 3 차원 움직임을 측정하 기 위해 23개의 반사 마커를 골반(Anterior Superior Iliac Spine; ASIS, Posterior Superior Iliac Spine; PSIS, Center Superior Iliac Spine ;CSIS, Iliac crest tubercle; ILIC, Femur greater trochanter; GT)과 다리(knee, ankle, heel, The 2nd metatarsal head; MTP2, The 5th metatarsal head; MTP5, The 5th metatarsal base; MTPJ)의 해부학적 위치에 부착하였다. 이를 10 대의 적외선 카메라(MX-T series, Vicon, UK)로 촬영하였으며, 보행 시점을 찾고 신체에 전달되는 충격력을 계산하기 위해 스트레인 게이지 (strain-gauge)형태 지면 반력 장비 2대를 보행 동선에 맞춰 설치하였다. 이때 샘플링 주파수는 각각 $200 \mathrm{~Hz}$ 와 $2000 \mathrm{~Hz}$ 로 설정하였다. 측정 장비를 통하여 얻은 데이 터는 Nexus 소프트웨어(Nexus 1.8.5, VICON, UK) 에 의해 동기화 및 저장되었다.

\section{실험 절차}

피험자는 $8 \mathrm{~m}$ 의 직선 주로를 $1.5 \mathrm{~m} / \mathrm{s}(5.4 \mathrm{~km} / \mathrm{h})$ 의 속도 로 걸었다. 미드솔 경도와 배낭 착용 여부는 무작위로 배정 하여 진행하였다. 수집 데이터는 수행 동작의 두 가지 판단 기준에 의해 선별적으로 측정되었다. 첫째, 보행 속도의 $2 \%$ 의 오차범위인 $1.47-1.53 \mathrm{~m} / \mathrm{s}$ 에 들어온 경우를 성공으로 간주하였다. 또한, 피험자의 오른발이 보행 경로 중 첫 번째 설치된 지면 반력 장비 안에 정확하게 들어왔을 때 성공 시 기로 판단하였다. 수행 과제마다 위의 기준에 부합하는 5회 의 성공 시기 데이터를 분석에 활용하였다.

\section{자료 처리}

본 연구에서는 보행 중 인체가 지면에 직접적인 힘을 가 해 전달되는 충격이 아닌, 발생한 충격에 대하여 미드솔 경 도가 인체에 미치는 효과를 찾고자 하였다. 그에 따라 발이 지면에 닿아 있는 지지기 구간(stance phase) 중, 발의 착 지 시점(heel contact: HC)부터 신체 중심이 앞으로 이동 하며 가장 높이 위치한 시점인 중간 지지기(midstance: $\mathrm{MS}$ )까지로, 이를 충격흡수 구간으로 설정하였다. 변화된 마 커좌표에 대한 데이터는 Butterworth 4th lowpass filter 를 통하여 잡음을 제거하였고, 이때 설정된 차단 주파수는 
$10 \mathrm{~Hz}$ 이다. 수집 데이터의 개인 내 편차를 줄이기 위하여 배 제 평균 방법을 적용하였으며, 이에 각 수행 과제별 성공 시 기 데이터는 5 개 중 양극배제평균방법을 통해 3 개를 선정하 여 분석에 활용하였다. 변인에 대한 산출은 다음과 같다.

\section{1) 충격현상의 변화}

지면접촉시간에 대한 변인은 발 뒷꿈치가 지면에 닿는 시 점(HC)부터 중간지지기(MS)까지 소요된 시간을 의미하며, 최대충격력은 충격흡수 구간 내 발생하는 수직 지면반력의 최댓값을 의미한다. 충격량은 분석구간 내 발생한 수직 지 면반력의 면적으로 계산하였다.

$$
\text { Impulse }=\sum_{i=1}^{n-1}\left\{\left(\frac{v G R F_{i}+v G R F_{i+1}}{2}\right) \times \Delta t\right\}
$$

부하율은 최대 수직력에 도달한 속도, 즉 기울기를 의미 한다. 발의 지면 접촉시점부터 최대 수직력이 발생하기까지 수직력의 차이를 소요시간으로 나누어 계산하였다.

$$
\text { loading rate }=\frac{\triangle F_{z}}{\Delta s}
$$

이때, 충격량과 부하율은 배낭 미착용 시에는 체중으 로 배낭을 착용한 경우에는 배낭의 무게를 포함한 체중 의 1.3 배로 정규화하여 하중의 영향을 통제하였다.

\section{2) 인체 충격흡수 전략}

하지관절의 최대 각속도는 단위 시간당 각 변화량으로 계 산하였으며, 그중 최댓값을 분석에 활용하였다. 하지관절의 최대 모멘트는 분석 구간 내 관절의 관성모멘트와 각가속도 의 곱으로, 각 대상자의 체중과 신장으로 정규화였다. 또한, 배낭을 착용한 경우에는 체중의 1.3 배로 계산하였다.

$$
\text { jointmoment }=I \times \alpha
$$

관절의 기계적 음의 일은 관절 모멘트 값을 대상자의 체 중과 신장으로 정규화하고, 이에 관절 각속도를 곱하여 분 석 구간 내 하지 관절 파워를 계산하였다. 이후 충격흡수 구 간 내 발생한 관절 파워의 면적을 계산하였다. 계산 식은 다 음과 같다.

$$
\begin{gathered}
\text { jointpower }=P_{j}=M_{j} \times w_{j} \\
\text { jointmechanical work }=\int P_{j} d t
\end{gathered}
$$

\section{3) 보행의 동적 안정성}

발목관절의 최대 각속도와 최대 모멘트는 위와 같은 방법 으로 계산하였고, 압력중심의 좌우편차는 분석 구간 내 좌 우방향에 대한 차이를 계산하였다. 그중 최대 편차를 분석 하여 활용하였다.

\section{통계 처리}

배낭 착용 여부와 미드솔 경도에 따른 보행 역학 변인의 차이를 검증하기 위하여 이원 변량 반복측정 분산 분석 (2-way(3x2) repeated measures ANOVA)을 수행하였 다. 사후 검증은 LSD 방법을 적용하였으며, 모든 유의 수준 은 $\alpha=.05$ 로 설정하였다.

\section{연구결과}

\section{충격 현상의 변화}

충격 현상의 변화에서 지면접촉시간은 배낭 착용 여부에 서 유의한 차이를 보였으며, 배낭 착용 시 접촉시간이 더 길 어졌다(F=9.462, $p$ <.05). 최대 충격력, 충격량, 그리고 부 하율은 배낭 착용 여부와 미드솔 경도 모두에서 유의한 차 이가 나타나지 않았다(Table 2).

\section{인체 충격흡수 전략}

인체 충격흡수 전략의 경우, 발목 관절에서 최대 발바닥 굽힘 속도는 Hard가 Soft보다 더욱 빠르게 나타났으며 $(\mathrm{F}=4.148, p<.05)$, 배낭 착용 여부에 따른 차이는 나타나지 않았다. 최대 발등 굽힘 모멘트는 미드솔 경도에 따른 유의 한 차이는 나타나지 않았지만, 배낭 착용을 했을 때 모멘트 크기가 감소하였다 $(\mathrm{F}=5.869, p<.05)$. 발목 관절의 기계적 음의 일은 Soft가 Medium보다 적은 양의 일을 수행하였고 $(\mathrm{F}=3.374, p<.05)$, 배낭 착용 여부에 따른 차이는 나타나지 않았다. 무릎 관절에서 최대 굽힘 속도는 배낭 착용 여부와 
Table 2. Result of shock phenomenon change according to midsole hardness and backpack

$($ Mean \pm SD)

\begin{tabular}{|c|c|c|c|c|c|}
\hline \multirow{3}{*}{ Variables } & & \multicolumn{2}{|c|}{ Backpack } & F-value(p-value) & \multirow{3}{*}{ Post-hoc } \\
\hline & & \multirow{2}{*}{$\mathrm{X}$} & \multirow{2}{*}{$\mathrm{O}$} & & \\
\hline & & & & M x B Interaction & \\
\hline \multirow{3}{*}{$\begin{array}{l}\text { Ground Contact time } \\
\text { (sec) }\end{array}$} & Soft & $0.324 \pm 0.025$ & $0.350 \pm 0.025$ & $0.260(0.772)$ & \\
\hline & Medium & $0.323 \pm 0.031$ & $0.343 \pm 0.027$ & $9.426(0.003)^{*}$ & \\
\hline & Hard & $0.320 \pm 0.029$ & $0.341 \pm 0.031$ & $0.084(0.920)$ & \\
\hline \multirow{3}{*}{$\begin{array}{c}\text { Impact Peak } \\
\text { (X: BW, O: 1.3BW) }\end{array}$} & Soft & $1.234 \pm 0.05$ & $1.233 \pm 0.051$ & $0.013(0.987)$ & \\
\hline & Medium & $1.236 \pm 0.061$ & $1.236 \pm 0.046$ & $0.000(0.989)$ & \\
\hline & Hard & $1.236 \pm 0.053$ & $1.236 \pm 0.059$ & $0.000(1.000)$ & \\
\hline \multirow{3}{*}{$\begin{array}{c}\text { Impulse } \\
\text { (X: BW, O: 1.3BW) }\end{array}$} & Soft & $556.89 \pm 39.73$ & $580.68 \pm 34.26$ & $0.264(0.769)$ & \\
\hline & Medium & $549.55 \pm 42.17$ & $570.10 \pm 33.49$ & $3.542(0.065)$ & \\
\hline & Hard & $554.67 \pm 40.42$ & $569.47 \pm 50.88$ & $0.063(0.939)$ & \\
\hline \multirow{3}{*}{$\begin{array}{c}\text { Loading rate } \\
\left(\mathrm{X}: \mathrm{BW} \times \mathrm{S}^{-1}, \mathrm{O}: 1.3 \mathrm{BW} \times \mathrm{s}^{-1}\right)\end{array}$} & Soft & $7.55 \pm 0.88$ & $7.20 \pm 0.83$ & $0.145(0.865)$ & \\
\hline & Medium & $7.57 \pm 1.07$ & $7.43 \pm 0.88$ & $1.427(0.238)$ & \\
\hline & Hard & $7.69 \pm 0.94$ & $7.33 \pm 0.8$ & $0.089(0.915)$ & \\
\hline
\end{tabular}

M: midsole, B:backpack, * $p<.05$

Table 3. Result of shock absorption strategy according to midsole hardness and backpack

$(\mathrm{Mean} \pm \mathrm{SD})$

\begin{tabular}{|c|c|c|c|c|c|}
\hline & & \multicolumn{2}{|c|}{ Backpack } & F-value(p-value) & \multirow[b]{2}{*}{ Post-hoc } \\
\hline & & $\mathrm{X}$ & $\mathrm{O}$ & $\begin{array}{c}\text { Midsole } \\
\text { Backpack } \\
\text { M x B Interaction }\end{array}$ & \\
\hline \multirow{12}{*}{ Ankle } & Peak plantarfles & city(deg*s-1) & & & \multirow{4}{*}{ Midsole: $\mathrm{H}<\mathrm{S}$} \\
\hline & Soft & $-177.67 \pm 24.11$ & $-171.95 \pm 25.43$ & $4.148(0.021)^{*}$ & \\
\hline & Medium & $-181.41 \pm 28.98$ & $-184.07 \pm 15.27$ & $0.204(0.654)$ & \\
\hline & Hard & $-200.85 \pm 24.60$ & $-194.91 \pm 32.67$ & $0.182(0.834)$ & \\
\hline & \multicolumn{4}{|c|}{ Peak dorsiflexion Moment(X: BW*m, O: 1.3BW*m) } & \\
\hline & Soft & $0.18 \pm 0.06$ & $0.15 \pm 0.04$ & $0.650(0.526)$ & \\
\hline & Medium & $0.19 \pm 0.05$ & $0.17 \pm 0.05$ & $5.869(0.019) *$ & \\
\hline & Hard & $0.20 \pm 0.06$ & $0.17 \pm 0.05$ & $0.039(0.962)$ & \\
\hline & Mechanical Ne & $\mathrm{rk}\left(\mathrm{X}: \mathrm{J} *\left(\mathrm{BW}^{*} \mathrm{~m}\right.\right.$ & : J*(1.3BW*m)- $)$ & & \multirow{4}{*}{ Midsole: $\mathrm{M}<\mathrm{S}$} \\
\hline & Soft & $-6.69 \pm 2.10$ & $-6.72 \pm 1.20$ & $3.374(0.042)^{*}$ & \\
\hline & Medium & $-10.58 \pm 3.33$ & $-8.51 \pm 1.87$ & $0.116(0.734)$ & \\
\hline & Hard & $-7.86 \pm 2.06$ & $-8.78 \pm 2.97$ & $1.216(0.305)$ & \\
\hline \multirow{12}{*}{ Knee } & \multicolumn{4}{|c|}{ Peak Flexion Velocity(deg*s-1) } & \\
\hline & Soft & $-146.10 \pm 22.10$ & $-152.33 \pm 22.45$ & $0.370(0.693)$ & \\
\hline & Medium & $-146.46 \pm 11.12$ & $-155.11 \pm 23.22$ & $0.906(0.346)$ & \\
\hline & Hard & $-154.28 \pm 24.84$ & $-155.93 \pm 27.30$ & $0.126(0.882)$ & \\
\hline & \multicolumn{4}{|c|}{ Peak Extension Moment(X: BW*m, O: 1.3BW*m) } & \\
\hline & Soft & $0.46 \pm 0.13$ & $0.54 \pm 0.12$ & $0.035(0.966)$ & \\
\hline & Medium & $0.44 \pm 0.11$ & $0.53 \pm 0.13$ & $6.336(0.015)^{*}$ & \\
\hline & Hard & $0.45 \pm 0.13$ & $0.54 \pm 0.16$ & $0.022(0.979)$ & \\
\hline & \multicolumn{4}{|c|}{ Mechanical Negative Work(X: J*(BW*m)-1, O : J*(1.3BW*m)- } & \\
\hline & Soft & $-10.29 \pm 5.59$ & $-16.90 \pm 6.97$ & $1.092(0.343)$ & \\
\hline & Medium & $-15.90 \pm 6.98$ & $-18.72 \pm 11.62$ & $6.579(0.013)^{*}$ & \\
\hline & Hard & $-12.87 \pm 6.48$ & $-19.90 \pm 10.28$ & $0.391(0.678)$ & \\
\hline
\end{tabular}


미드솔 경도 모두에서 통계적으로 유의한 차이가 나타나지 않았다. 최대 폄 모멘트는 배낭 착용 시 유의하게 증가하였 으며(F=6.336, $p$ 〈.05), 미드솔 경도에 따른 차이는 나타나 지 않았다. 무릎 관절의 기계적 음의 일 또한 배낭을 착용함 에 따라 증가하였으며(F=6.579, $p$ <.05), 미드솔 경도에 의 한 차이는 나타나지 않았다(Table 3 ).

\section{보행의 동적 안정성}

보행의 동적 안정성은 분석 구간 내 발목 관절의 최대 바 깥 꺾임 속도, 최대 안쪽 꺾임 모멘트, 그리고 기계적 음의 일 모두 배낭 착용 여부와 미드솔 경도에 따른 유의한 차이 를 나타내지 않았다. 압력 중심의 좌우 편차는 배낭 착용 시 유의하게 감소하였으며(F=4.423, $p$ 〈.05), 미드솔 경도에 따른 통계적 차이는 나타나지 않았다(Table 4).

\section{논 의}

본 연구에서는 배낭을 착용함에 따라 트레킹화 미드솔 경
도가 인체 보행의 운동역학적 변인에 어떠한 영향을 미치는 지 알아보고, 이에 따라 배낭 보행 시 근 피로 절감과 역학적 안정성에 효과적인 미드솔를 제시하고자 하였다.

인체 보행 시 나타나는 충격 현상과 관련하여 지면 접촉 시간에서 트레킹화의 미드솔에 따른 통계적 유의한 차이는 나타나지 않았지만, 배낭 착용 여부에 따라서는 통계적 유 의한 차이가 나타났다. Charteris(1998)는 배낭 무게가 증 가함에 따라 지지구간의 지면접촉시간이 증가하였다고 보 고하였으며, 이러한 현상을 기계적 스트레스를 덜 받기 위 해 인체 보행에 변화를 준 것이라고 보고하였다. 이는 본 연 구와 같은 결과라고 할 수 있다. 또한, Ryue 등(2019)는 미 드솔 경도가 낮을수록 지면접촉시간이 증가하였다고 보고 하였으며, 이는 미드솔 경도가 에너지 흡수를 위한 구성물 질 변형의 차이에 의한 것으로 설명하였다. 이는 본 연구와 는 다른 결과라고 할 수 있다. 그러나 평균적으로 경도가 낮 을수록 지면접촉시간이 증가하는 성향을 보이는 것은 미드 솔의 쿠션기능이 충격을 흡수하는데 있어 일정 부분 보조한 것이라고 생각된다. 하지만 본 연구에서 사용한 Soft 미드 솔 경도가 기존연구(45 55 vs 63)보다 높아 그에 대한 변 화가 적었을 것으로 예상된다.

Table 4. Result of gait dynamic stability according to midsole hardness and backpack

(Mean \pm SD)

\begin{tabular}{|c|c|c|c|c|c|}
\hline & & \multicolumn{2}{|c|}{ Backpack } & F-value(p-value) & \multirow{4}{*}{ Post-hoc } \\
\hline & & \multirow{3}{*}{$\mathrm{X}$} & \multirow{3}{*}{$\mathrm{O}$} & Midsole & \\
\hline & & & & Backpack & \\
\hline & & & & M x B Interaction & \\
\hline \multirow{12}{*}{ Ankle } & \multicolumn{4}{|c|}{ Peak Eversion Velocity(deg*s-1) } & \\
\hline & Soft & $-77.33 \pm 19.69$ & $-76.96 \pm 13.39$ & $1.606(0.210)$ & \\
\hline & Medium & $-77.79 \pm 24.59$ & $-75.51 \pm 15.52$ & $0.158(0.693)$ & \\
\hline & Hard & $-87.64 \pm 23.56$ & $-84.53 \pm 11.74$ & $0.028(0.972)$ & \\
\hline & \multicolumn{4}{|c|}{ Peak Inversion Moment(X: BW*m, O: 1.3BW*m) } & \\
\hline & Soft & $0.05 \pm 0.04$ & $0.06 \pm 0.06$ & $0.213(0.809)$ & \\
\hline & Medium & $0.05 \pm 0.04$ & $0.07 \pm 0.06$ & $1.294(0.260)$ & \\
\hline & Hard & $0.04 \pm 0.03$ & $0.06 \pm 0.05$ & $0.091(0.913)$ & \\
\hline & \multicolumn{4}{|c|}{ Mechanical Negative Work on Frontal plane(X: J*(BW*m)-1, O : J*(1.3BW*m)-) } & \\
\hline & Soft & $-0.52 \pm 0.52$ & $-0.74 \pm 0.69$ & $0.330(0.720)$ & \\
\hline & Medium & $-0.37 \pm 0.36$ & $-0.67 \pm 0.61$ & $1.753(0.191)$ & \\
\hline & Hard & $-0.63 \pm 0.44$ & $-0.66 \pm 0.50$ & $0.323(0.726)$ & \\
\hline \multirow{4}{*}{ COP } & \multicolumn{4}{|c|}{ medio-lateral deviation(cm) } & \\
\hline & Soft & $3.51 \pm 1.82$ & $2.51 \pm 1.17$ & $1.342(0.270)$ & \\
\hline & Medium & $3.29 \pm 1.23$ & $2.59 \pm 1.12$ & $4.423(0.040)^{*}$ & \\
\hline & Hard & $2.61 \pm 1.31$ & $2.18 \pm 1.04$ & $0.235(0.791)$ & \\
\hline
\end{tabular}


최대 충격력과 충격량, 부하율과 같이 힘의 크기가 포함 된 변인들은 미드솔 경도와 배낭 착용 여부 모두 유의한 차 이를 보이지 않았다. 이는 신체에 전달되는 충격을 유지하 거나 줄이기 위하여 외부 충격과 발이 딛고 있는 표면과 같 은 환경적 변화에 대하여 각기 다른 반응을 한다고 보고하는 이전 연구들과 상응되는 결과로 보인다(Cole, Nigg, Fick, \& Morlock, 1995; Frederick, 1986; Nigg et al., 1987). 그러나 Dahl 등(2016)은 하중이 감소함에 따라 무릎의 굽 힘 각도가 작아지며, 무릎의 굴곡뿐만 아니라 몸통 굴곡에 도 영향을 미쳐 더 작은 부하율을 갖고 관절의 스트레스를 줄일 수 있다고 하였으며, 이종훈(2009)은 부하를 완충시키 기 위해 착지 후 다음 체중이 착지발로 이동할 때 무릎을 덜 구부리게 된다고 설명하였다. 본 연구결과에서는 통계적으 로 유의한 차이는 없었지만 부하율이 배낭을 착용함에 따라 감소하는 것을 보면 착지 시 발생하는 충격에 대한 인체가 취하는 보호 전략 중 하나일 가능성이 있다고 판단된다.

또한, 본 연구 결과 발목 관절의 최대 발바닥 굽힘 속도는 미드솔 경도에 따라 유의한 차이를 보였으며, 딱딱한 신발 이 부드러운 신발보다 빠르게 나타났다. 일반적으로 충격흡 수 구간에서 발이 지면과 편평(flat)해지는 '통제된 롤 오프 (controlled roll-off)' 과정에서 최대 속도가 발생하며 (Neptune, Kautz, \& Zajac, 2001), 착지 시 완충 기능이 부족할 때 더욱 빠르게 발바닥 굽힘 자세를 만들어 발바닥의 넓은 면적이 지면과 접촉하여 외부 충격을 분산시킨다 (Frederick, 1986). 이러한 발바닥 굽힘 동작은 앞정강근 (tibialis anterior)의 신장성 수축에 의해 제어되며(Ebig, Lephart, Burdett, Miller, \& Pincivero, 1997), 반복적 인 보행 동작에서 딱딱한 신발의 미비한 쿠션 기능이 앞정강 근의 사용 요구를 증가시킨다면 장거리 트레킹 시 조기에 피 로가 유발될 것으로 생각된다.

발목 관절의 최대 발등 굽힘 모멘트는 배낭을 착용함에 따라 유의하게 감소하였으나 무릎 관절의 최대 폄 모멘트는 증가하였다. 이는 배낭이라는 체중이외의 추가적인 하중에 대하여 인체는 근위 관절을 활용하여 더욱 큰 힘을 안정적으 로 발현하는 보행 전략을 취하는 것으로 보인다. 실제 Quesada와 3명(2000)은 배낭 무게를 다르게 하여 장시간 보행을 수행하였을 때 무릎 관절에서만 피로 후에 최대 폄 모멘트가 유의하게 감소하는 결과를 제시하였다. 그리고 넙 다리네갈래근(quadriceps femoris)의 피로가 영향을 미 쳤을 것이며, 충격흡수 기능의 약화는 과 사용 손상으로 이
어질 것이라고 보고하였다(Chow et al., 2005). 그러나 본 연구에서는 피로를 유발하지 않은 보행 동작의 차이를 확인 한 다소 제한된 결과로 보인다.

관절의 기계적 일에 대한 결과를 살펴보면, 발목 관절에 서 미드솔 경도에 따른 유의한 차이가 나타났으며, 부드러 운 신발 착용 시 낮은 기계적 일의 양을 수행하였다. 또한, 무릎 관절에서도 배낭 착용 여부에 따라 기계적 일에 대한 통계적 차이가 나타났다. 발목관절은 착지 시 발, 무릎, 고관 절, 척추로 전이되고, 발목, 무릎, 고관절을 통하여 부하의 전이를 최소화한다(Dufek and Bates, 1990). 따라서, 이 는 무릎의 최대 폄 모멘트가 증가한 것과 연관이 있을 것으 로 보이며, 충격흡수 구간에서 무릎관절에 의해 발현되는 기계적 일은 충격력의 완충 역할이라는 측면에서 운동역학 적 의미로 바라볼 수 있을 것으로 판단된다.

압력 중심의 좌우 편차는 배낭을 착용한 경우 유의하게 작아졌다. 선행연구를 살펴보면, 하중의 증가가 동작의 균 형을 무너뜨려 불안정한 자세를 유도하며, 낙상의 위험을 높인다고 보고하였다(Capodaglio et al., 2009, Hue et al., 2007). 이는 본 연구결과와는 상반된 결과이다. 이는 하 중이 증가하였음에도 보행 속도를 유지하기 위해 전방 움직 임에 집중한 결과로 보인다.

본 연구는 지면의 충격과 미드솔 특성 차이를 일차적으로 경험하는 발목 관절의 관상면 움직임과 보행의 동적 안정성 에 초점을 두어 분석하였다. 그러나 본 연구 결과에서 최대 바깥ㄲㄲㄲ임 속도, 최대 안쪽 꺾임 모멘트, 관절의 기계적 음의 일 모두 미드솔 경도와 배낭 착용 여부에 따른 상호작용은 나타나지 않았다. 이는 본 연구에서 사용한 미드솔의 경도 차이로는 뒤꿈치의 골격 구조가 상대적으로 단순하여 지표 면의 특성에 대한 감도 및 조정 능력이 민감하게 반응하지 못하는 것으로 보인다.

\section{결론 및 제언}

미드솔 경도와 배낭 착용이 보행에 미치는 영향을 분석한 결과, 본 연구에서 사용한 미드솔 경도 차이로는 배낭을 착 용하여도 보행의 역학적 움직임에 영향을 미치지 못하는 것 으로 보인다. 따라서 추후 연구에서는 신발의 유무 또는 근 피로 유발을 통해 미드솔의 효과를 조사하는 것이 필요할 것 으로 보인다. 


\section{참고문헌}

Aerts, P., \& Clercq, D. D. (1993). Deformation characteristics of the heel region of the shod foot during a simulated heel strike: the effect of varying midsole hardness. Journal of sports sciences, 11(5), 449-461.

Arndt, A., Westblad, P., Ekenman, I., \& Lundberg, A. (2003). A comparison of external plantar loading and in vivo local metatarsal deformation wearing two different military boots. Gait \& posture, 18(2), 20-26.

Bentley, T. A., Page, S., \& Walker, L. (2004). The safety experience of New Zealand adventure tourism operators. Journal of Travel Medicine, 11(5), 280-286.

Bergmann, G., Kniggendorf, H., Graichen, F., \& Rohlmann, A. (1995). Influence of shoes and heel strike on the loading of the hip joint. Journal of biomechanics, 28(7), 817-827.

Capodaglio, P., Vismara, L., Menegoni, F., Baccalaro, G., Galli, M., \& Grugni, G. (2009). Strength characterization of knee flexor and extensor muscles in Prader-Willi and obese patients. BMC musculoskeletal disorders, 10(1), 1-8.

Charteris, J. (1998). Comparison of the effects of backpack loading and of walking speed on foot-floor contact patterns. Ergonomics, 41(12), 1792-1809.

Chow, D. H., Kwok, M. L., Au-Yang, A. C., Holmes, A. D., Cheng, J. C., Yao, F. Y., \& Wong, M. S. (2005). The effect of backpack load on the gait of normal adolescent girls. Ergonomics, 48(6), 642-656.

Cigoja, S., Vienneau, J., Nigg, S. R., \& Nigg, B. M. (2019). The effects of midsole bending stiffness on ball speed during maximum effort soccer kicks. Footwear Science, 11(3), 153-160.

Cole, G. K., Nigg, B. M., Fick, G. H., \& Morlock, M. M. (1995). Internal loading of the foot and ankle during impact in running. Journal of applied biomechanics, 11(1), 25-46.

Day, E., \& Hahn, M. (2020). Optimal footwear longitudinal bending stiffness to improve running economy is speed dependent. Footwear Science, 12(1), 3-13.

Dahl, K. D., Wang, H., Popp, J. K., \& Dickin, D. C. (2016). Load distribution and postural changes in young adults when wearing a traditional backpack versus the
BackTpack. Gait \& posture, 45(1), 90-96.

De Wit, B., De Clercq, D., \& Lenoir, M. (1995). The effect of varying midsole hardness on impact forces and foot motion during foot contact in running. Journal of Applied Biomechanics, 11(4), 395-406.

Dixon, S., Waterworth, C., Smith, C., \& House, C. (2003). Biomechanical analysis of running in military boots with new and degraded insoles. Medicine \& Science in Sports \& Exercise, 35(3), 472-479.

Dufek, J. S., \& Bates, B. T. (1990). The evaluation and prediction of impact forces during landings. Medicine \& Science in Sports \& Exercise, 22(3), 370-377.

Ebig, M., Lephart, S. M., Burdett, R. C., Miller, M. C., \& Pincivero, D. M. (1997). The effect of sudden inversion stress on EMG activity of the peroneal and tibialis anterior muscles in the chronically unstable ankle. Journal of orthopaedic \& sports physical therapy, 26(2), 73-77.

Faulhaber, M., Pocecco, E., Niedermeier, M., Ruedl, G., Walter, D., Sterr, R., Ebner, H., Schobersberger, W., Burtscher, M. (2017). Fall-related accidents among hikers in the Austrian Alps: A 9-year retrospective study. BMJ open sport \& exercise medicine, 3(1), 1-7.

Finestone, A., Giladi, M., Elad, H., Salmon, A., Mendelson, S., Eldad, A., \& Milgrom, C. (1999). Prevention of stress fractures using custom biomechanical shoe orthoses. Clinical Orthopaedics and Related Research ${ }^{\circledR}, 360(1)$, 182-190.

Frederick, E. C. (1986). Kinematically mediated effects of sport shoe design: a review. Journal of sports sciences, 4(3), 169-184.

Ha, S., Ryu, S., \& Gil, H. J. (2020). Do the Mechanical Properties of Midsole Affect Body Shock and Stabilization for Lower Extremity During Running? Journal of the Ergonomics Society of Korea, 39(2), 99-108.

Haisman, M. F. (1988). Determinants of load carrying ability. Appfied Ergonomics, 19(2), 111-121.

Hue, O., Simoneau, M., Marcotte, J., Berrigan, F., Doré, J., Marceau, P., Marceau, S., Tremblay, A., Teasdale, N. (2007). Body weight is a strong predictor of postural stability. Gait \& posture, 26(1), 32-38.

Knapik, J. J., Swedler, D. I., Grier, T. L., Hauret, K. G., Bullock, S. H., Williams, K. W., Darakjy, S. S., Lester, M. 
E., Tobler, S. K. Jones, B. H. (2009). Injury reduction effectiveness of selecting running shoes based on plantar shape. The Journal of Strength \& Conditioning Research, 23(3), 685-697.

Lafortune, M. A., Hennig, E. M., \& Lake, M. J. (1996). Dominant role of interface over knee angle for cushioning impact loading and regulating initial leg stiffness. Journal of biomechanics, 29(12), 1523-1529.

Law, M. H., Choi, E. M., Law, S. H., Chan, S. S., Wong, S. M., Ching, E. C., Chan, Z. Y., Zhang, J. H., Lam, G. W., Lau, F. O., Cheung, T. (2019). Effects of footwear midsole thickness on running biomechanics. Journal of sports sciences, 37(9), 1004-1010.

Lieberman, D. E., Venkadesan, M., Werbel, W. A., Daoud, A. I., D’andrea, S., Davis, I. S., Mang’Eni, R. O., Pitsiladis, Y. (2010). Foot strike patterns and collision forces in habitually barefoot versus shod runners. Nature, 463(28), 531-535.

Monasterio, E. (2005). Accident and fatality characteristics in a population of mountain climbers in New Zealand. The New Zealand Medical Journal (Online), 118(1208), 1-8.

Neptune, R., Kautz, S., \& Zajac, F. (2001). Contributions of the individual ankle plantar flexors to support, forward progression and swing initiation during walking. Journal of biomechanics, 34(11), 1387-1398.

Nigg, B., Bahlsen, H., Luethi, S., \& Stokes, S. (1987). The influence of running velocity and midsole hardness on external impact forces in heel-toe running. Journal of biomechanics, 20(10), 951-959.

Nigg, B., Hintzen, S., \& Ferber, R. (2006). Effect of an unstable shoe construction on lower extremity gait characteristics. Clinical Biomechanics, 21(1), 82-88.

Perry, S. D., Radtke, A., \& Goodwin, C. R. (2007). Influence of footwear midsole material hardness on dynamic balance control during unexpected gait termination. Gait \& posture, 25(1), 94-98.

Price, C., Cooper, G., \& Jones, R. (2015). The manipulation of midsole properties to alter impact characteristics in walking. Footwear Science, 7(1), 9-16.

Quesada, P. M., Mengelkoch, L. J., Hale, R. C., \& Simon, S. R. (2000). Biomechanical and metabolic effects of varying backpack loading on simulated marching. Ergonomics,
43(3), 293-309.

Ryue, J., Cho, S., Lee, J., \& Lee, K. (2019). Effect of shoe midsole hardness and resilience on running performance. Footwear Science, 11(1), 141-142.

Schwameder, H., Kraft, S., \& Alexander, N. (2017). Lower extremity muscle activities and gait kinematics in hiking using trekking shoes and high-cuff hiking boots. ISBS Proceedings Archive, 35(1), 189.

Sinclair, J. (2017). The influence of minimalist, maximalist and conventional footwear on impact shock attenuation during running. Movement \& Sport Sciences-Science \& Motricité, 95(1), 59-64.

Stacoff, A., Denoth, J., Kaelin, X., \& Stuessi, E. (1988). Running injuries and shoe construction: some possible relationships. Journal of Applied Biomechanics, 4(4), 342-357.

Stefanyshyn, D., \& Nigg, B. (2000). Energy aspects associated with sport shoes. Sportverletzung:Sportschaden, 14(3), 82-89.

Sterzing, T., Schweiger, V., Ding, R., Cheung, J. T.-M., \& Brauner, T. (2013). Influence of rearfoot and forefoot midsole hardness on biomechanical and perception variables during heel-toe running. Footwear Science, 5(2), 71-79.

Twombly, S. E., \& Schussman, L. C. (1995). Gender differences in injury and illness rates on wilderness backpacking trips. Wilderness \& Environmental Medicine, 6(4), 363-376.

Voloshin, A. S., \& Wosk, J. (1983). Shock absorption of meniscectomized and painful knees: a comparative in vivo study. Journal of biomedical engineering, 5(2), 157-161.

Wang, L., Hong, Y., \& Li, J. X. (2012). Durability of running shoes with ethylene vinyl acetate or polyurethane midsoles. Journal of sports sciences, 30(16), 1787-1792.

김은경. (2000). 20 세기 신발 디자인 연구.

김희성, \& 이재섭. (2010). 트레킹(trekking)시장세분화를 통한 상 품개발 방안. 관광레저연구, 22(1), 271-287.

이종훈. (2009). 기능성 스프링신발과 일반운동화의 운동역학적 비 교분석. 한국운동역학회지, 19(3), 581-592.

유찬일, 원용관, \& 김정자. (2015). 미드솔의 반발탄성이 러닝화의 생체역학적 특성에 미치는 영향. 한국운동역학회지, 25(1), 103-111.

Diffen, 'Hiking vs Trekking.' 2020.05.26.https://www.diffen. 
com/difference/Hiking_vs_Trekking(접속일:2020.05.27.). 조선닷컴. ‘등산, 트레킹 인구 2,600만 시대 $\cdots$ 트렌드가 바뀌고 있
다.’ 2019.06.10., http://san.chosun.com/site/data/html_dir/ 2019/05/21/2019052101943.html(접속일:2020.05.27).

\title{
배낭 착용에 따른 트레킹화 미드솔(midsole)경도가 보행에 미치는 영향
}

\author{
조승현 ${ }^{1}$, 김관태 ${ }^{1}$, 이정호 ${ }^{2}$, 김미선 $^{3}$ \\ 1국민대학교 \\ ${ }^{2} \mathrm{~K} 2$ 한국신발연구소 \\ 3한국스포츠정책과학원 연구원
}

[목적] 본 연구는 배낭을 착용함에 따라 트레킹화 미드솔 경도가 인체 보행 역학에 미치는 영향을 규명하는 데 목적이 있다. [방법] 총 10 명의 성인남성(연령:23.20 \pm 1.33 세, 신장: $1.72 \pm 0.03 \mathrm{~cm}$, 체중: $67.60 \pm 5.95 \mathrm{~kg}$ )을 대상으로 각기 다른 미드솔 경도(Soft, Medium, Hard)와 배낭(체중의 30\%)의 착용여부를 무작위로 선정하여 $8 \mathrm{~m}$ 의 구간을 $1.5 \mathrm{~m} / \mathrm{s}$ 속력으로 걷도록 실시하였다. 보행 속도 통제를 위해 구간 속력 측정기를 활용하였고, 신체 움직임에 대한 측정을 위해 10대의 적외선 카메라(Vicon motion capture system, UK)와 지면반력기 (AMTI, ORG-6, US)를 사용하였다. [결과] 첫째, 충격현상의 변화에서 배낭 착용 시 지면접촉시간( $p$ 〈.05)이 더 길어졌다. 둘째, 인체 충격흡수 전략에서 발목관절에서 최대 발바닥 굽힘 속도가 Hard가 Soft보다 더 빠르 게 나타났으며, 최대 발등 굽힘 모멘트가 배낭 착용 시 감소하였다( $p$ 〈.05). 또한, 무릎의 최대 폄 모멘트는 배 낭 착용 시 유의하게 증가하였다. 넷째, 기계적 음의 일에서는 발목관절은 Soft가 Medium보다 적은 양의 일을 수행하였고, 무릎관절은 배낭을 착용함에 따라 증가하였다( $p 〈 .05)$. [결론] 본 연구의 결과 본 연구에서 사용한 미드솔 경도 차이로는 배낭을 착용하여도 보행의 역학적 움직임에 영향을 미치지 못하는 것으로 보이며, 추후 연구에서는 신발의 유무 또는 근 피로 유발을 통해 미드솔의 효과를 조사하는 것이 필요할 것으로 사료된다.

주요어: 미드솔, 배낭, 충격 현상의 변화, 인체 충격 현상 변화, 기계적 음의 일 